\title{
Untying the Gordian knot: unravelling what influences quality of life in asthma patients
}

\author{
Ralph R. Turner ${ }^{1}$ and Christopher Landon ${ }^{2}$ \\ Affiliations: 'Scotch Mountain Associates, Gainesville, VA, USA. ${ }^{2}$ Pediatric Diagnostic Center, Ventura, CA, USA.
}

Correspondence: Ralph R. Turner, Scotch Mountain Associates, 13248 Fieldstone Way, Gainesville, VA 20155, USA. E-mail: scotchmtassociatesवgmail.com

。 @ERSpublications

A new study reports that non-symptom aspects of asthma control and generic QOL best predict asthma-specific QOL http://ow.ly/PWNMB

Readers of the European Respiratory Journal are well aware that asthma is an important healthcare concern. Current treatments include glucocorticoids, leukotriene antagonists, long-acting bronchodilators, monoclonal antibodies directed at interleukin (IL)5, IgE, and IL13, and a degree of chemotherapy in cost and degree of complexity becoming close kin to individualised treatment for cancer, and yet hospitalisation and emergency care with substantial impact on quality of life continues. Alexander has yet to winter at Gordium, unsheathe his sword and slice the knot. In this issue of the European Respiratory Journal, SтUску et al. [1] present work that disentangles major contributors to asthma-specific quality of life that often have been confounded in patient measures reported in previous research [2]. By doing so, the authors have clarified how asthma symptoms, asthma control and general health-related quality of life, uniquely and in the aggregate, influence asthma-specific quality of life. This work points the way for more focussed and precise measures which will, in turn, help inform the discussion about treatment options and healthcare services delivery.

The most recent data from the US Centers for Disease Control reveal an overall prevalence of $7.3 \%$ in the USA with highest percentages among those aged $<18$ years (8.3\%), females (8.3\%), African-American (9.9\%), and those having the lowest incomes (10.9\%) [3]. According to the Global Burden of Asthma report for 2004, prevalence in Europe ranged from $16.1 \%$ in the UK and Ireland to $4.9 \%$ in Scandinavia and the Baltic states with an average prevalence across Europe of 8.3\% [4]. Asthma comes with a price. During 2010 in the USA, there were 1.8 million emergency department visits due to asthma, with 439000 asthma-related hospitalisations. Asthma costs some $\$ 56$ billion in the USA, $90 \%$ of which are direct medical costs, mainly due to hospitalisations [5]. For adults, asthma results in work absenteeism and loss of productivity with $>14$ million work days lost each year while, among children aged 5-17 years, it is one of the leading causes of school absences, accounting for an annual loss of more than 10.5 million school days [6].

Clinical measures - asthma symptoms, severity and control - while important for understanding disease status and treatment progress, fall short of providing information about the full impact of asthma on patient functioning and wellbeing. The 2010 National Institutes of Health expert panel meeting cited this problem and served as a basis for the work reported by Stucky and co-workers: “...because the burden of asthma as measured by symptoms or activity levels does not give a complete picture, an assessment of the patient's perception of the impact of impairments on his or her QoL [quality of life] remains essential" [7].

As advanced psychometric methods and techniques that have been applied with success in other disciplines, notably psychological testing, educational assessment and rehabilitation research, are brought to bear in clinical research settings, measurement of patient-reported outcomes has become more robust and precise. Stucky and co-workers drew upon their experience with the PROMIS (Patient Reported Outcomes Measurement Information System) initiative [8] as well as the RAND Corporation's long-standing work in

Received: June 152015 | Accepted after revision: July 212015

Conflict of interest: None declared.

Copyright OERS 2015 
health outcomes assessment [9-11] to develop the RAND negative Impact of Asthma on Quality of Life (RAND-IAQL). Designed to avoid confounding quality of life with asthma symptomatology and functional impairment, the IAQL focuses on content important to people with asthma [1]. Using IAQL along with other measures of asthma symptoms, asthma control and generic quality of life, the authors found that non-symptom aspects of asthma control and generic quality of life accounted for the greatest proportion of variance in predicting asthma-specific quality of life. This finding has implications for understanding more precisely how asthma impacts patient wellbeing.

Understanding this relationship has the potential to help inform healthcare providers in crafting effective treatment plans for patients with asthma. Important among these is concern for increasing adherence with asthma medications. SHELL [12] indicated that children with severe asthma have treatment regimens approaching those of AIDS patients, with some taking as many as eight medications per day. Interventions to increase adherence include behavioural and educational programmes [13], electronic reminder systems [14], and assessing barriers to adherence, including understanding patient preference and satisfaction $[15,16]$. This is especially important for minority patients for whom access to care is limited [17], and family lack of understanding of the disease may impede effective treatment [18].

All of these approaches require measurement systems that meet the test of "fit for purpose" in terms of validity, reliability, sensitivity, responsiveness and precision. SтUску et al. [1] have shown that when those standards are met, the value-added information has the potential to help achieve the goal of better overall asthma control.

\section{References}

1 Stucky BD, Sherbourne CD, Orlando Edelen M, et al. Understanding asthma-specific quality of life: moving beyond asthma symptoms and severity. Eur Respir J 2015; 46: 680-687.

2 Chen $\mathrm{H}$, Gould MK, Blanc P, et al. Asthma control, severity, and quality of life: quantifying the effect of uncontrolled disease. J Allergy Clin Immunol 2007; 120: 396-402.

3 Asthma. Centers for Disease Control and Prevention. Available from www.cdc.gov/asthma/asthmadata.htm Date last accessed: June 3, 2015.

4 Masoli M, Fabian D, Holt S, et al. Global Burden of Asthma, 2004. Global Initiative for Asthma. Available from www.ginasthma.org/Global-Burden-of-Asthma Date last accessed: June 3, 2015.

5 United States Environmental Protection Agency. Asthma Facts. March 2013. Available from www.epa.gov/asthma/ pdfs/asthma_fact_sheet_en.pdf. Date last accessed: June 3, 2015.

6 CDC. National Center for Environmental Health. Asthma's Impact on the Nation: Data from the CDC National Asthma Control Program. 2014. Available from www.cdc.gov/asthma/impacts_nation/asthmafactsheet.pdf Date last accessed: June 3, 2015.

7 Wilson SR, Rand CS, Cabana MD, et al. Asthma outcomes: quality of life. J Allergy Clin Immunol 2012; 129: S88-S123.

8 Patient Reported Outcomes Measurement Information System (PROMIS) ${ }^{\circ}$. Available from www.nihpromis.org Date last accessed: June 4, 2015.

9 Brook RH, Ware JE Jr, Davies-Avery A, et al. Overview of adult health measures fielded in Rand's health insurance study. Med Care 1979; 17: 7 Suppl., iii-iix, 1-131.

10 Ware JE Jr. Standards for validating health measures: definition and content. J Chronic Dis 1987; 40: 473-480.

11 Stewart A, Ware JE Jr, Brook RH. The meaning of health: understanding functional limitations. Med Care 1977; 15: 939-952.

12 Shell ER. Does Civilization Cause Asthma? The Atlantic Monthly 2000; 285: 90-100.

13 Morton RW, Everard ML, Elphick HE. Adherence in childhood asthma: the elephant in the room. Arch Dis Child 2014; 99: 949-953.

14 Tran N, Coffman J, Sumino K, et al. Patient reminder systems and asthma medication adherence: a systematic review. J Asthma 2014; 51: 536-543.

15 Turner RR, Testa MA, Hayes JF, et al. Validation of the allergic rhinitis treatment satisfaction and preference scale. Allergy Asthma Proc 2013; 34: 551-557.

16 Berger WE, Prenner B, Turner R, et al. A patient preference and satisfaction study of ciclesonide nasal aerosol and mometasone furoate aqueous nasal spray in patients with perennial allergic rhinitis. Allergy Asthma Proc 2013; 34: 542-550.

17 McLean DE, Bowen S, Drezner K, et al. Asthma among homeless children: undercounting and undertreating the underserved. Arch Pediatr Adolesc Med 2004; 158: 244-249.

18 Lara M, Duan N, Sherbourne C, et al. Differences between child and parent reports of symptoms among Latino children with asthma. Pediatrics 1998; 102: E68. 